\title{
Analysis of Cohesivenes in Descriptive text Written by Undergraduate Students
}

\author{
Muhammad Zaki Pahrul Hadi \\ Universitas Bumigora \\ zakipahrul@universitasbumigora.ac.id
}

\begin{abstract}
Cohesiveness or the use of cohesive devices is a critical aspect of writing skill. It is one of the primary characteristics that should be mastered when writing well. The purpose of this article was to examine the use of cohesive devices in descriptive text written by undergraduate students in the Banking Department of STIE KERJASAMA Yogyakarta's third semester. This study examined the use of cohesive devices in each of the students' descriptive texts. The study's data set consisted of ten texts. The study identified four significant findings by employing a mixed research design and drawing on Halliday and Hasan's (1976) influential theory of cohesion. To begin, students' English texts contain a variety of cohesive devices (reference, conjunction, substitution, ellipses, and lexical cohesion). Whereas there are three types of cohesive devices that are frequently used in texts: reference, lexical cohesion, and conjunction. The study's findings have repercussions for pedagogy, theory, academic writing, and future research.
\end{abstract}

Keywords: cohesiveness, cohesive devices, descriptive text, English texts.

\section{INTRODUCTION}

Language is composed of two major abilities: productive and receptive abilities. Speaking and writing are considered productive abilities, whereas reading and listening are considered receptive abilities. Among all language skills, writing is considered the most difficult for language learners to master. However, Brown (2000:294) asserts that in order to master the English language, students must be exposed to all four basic skills. When students attempt to practise writing, they encounter numerous obstacles. Indeed, writing is the ability of students to create sentences that are organised and connected in specific ways. 
One of the most critical aspects of writing ability to consider is the use of cohesion in each paragraph. A good piece of writing should be coherent. It's difficult to comprehend the meaning of a sentence if the written text is incoherent. According to Halliday and Hasan (1976:2), a text is best viewed as a semantic unit, not as a unit of form, but as a unit of meaning. This means that a text should not only be in the form of a sentence but should also be meaningful and simple to comprehend. Numerous studies on cohesive studies have been conducted in the past by numerous researchers. Ninsiana (2014) and Afful. J.B.A and Nartey M. conducted several of these studies (2014).

Ninsiana (2014) examined the grammatical-cohesion devices used in the Indonesian translation of English bidding documents, dubbed 'Dokumen Tender'. It seeks to identify and characterise the grammatical-cohesion-marking translation of Bidding Document, also known as Dokumen Tender. The research employed a qualitative descriptive approach in conjunction with an established case study and orientation to such a product through the lens of a holistic critical method that examines objective, genetic, and affective dimensions. The study's findings indicated that: First, grammatical cohesion devices in Bidding Documents were translated into Dokumen Tender. These devices included a reference marker, substitution, ellipsis, and conjunction. The Bidding Document contains several grammatical cohesion devices that experience change and non-change in cohesion markers. This is because the grammatical structure, reference, and social culture context are all different. Second, there are six distinct categories of translation techniques: literal, amplification, modulation, reduction, and linguistic amplification. Third, the translation of the meaning of cohesion-marking in the Bidding Document can be deemed satisfactory. This is based on expert assessments that 89.77 percent of cohesion marking translation is considered accurate, 5.61 percent is considered less accurate, and 4.62 percent is considered inaccurate. Acceptability or worthiness of cohesion devices is stated as very good in this Bidding Document. The level of worthiness for the cohesion-devices in this Bidding Document is 88.12 percent, while 5.94 percent is deemed unnatural or improper. 
The second previous study related to the topic was conducted by Afful. J.B.A and Nartey M. (2014). They examines grammatical cohesion in the Language and Literature abstracts of postgraduate dissertations presented to the Department of English of a public university in Ghana - the University of Cape Coast (UCC). A total of 50 abstracts (25 each from Language and Literature) constituted the data set for the study. Using mixed research design and drawing on Halliday and Hasan's (1976) influential theory of cohesion, the study points to three key findings. First, of Halliday and Hasan's four grammatical cohesive devices (that is, conjunction, reference, substitution, and ellipses) reference and conjunction are preponderantly used. Second, the use of these grammatical devices in the Language and Literature abstracts evinces more similarities than differences. Third, although undergraduate students studying English at the University of Cape Coast do use a range of grammatical cohesive devices, they seem to lack sophistication in their use. The findings of this study have implications for pedagogy, theory, academic writing and further research. In this paper, we have explored the extent to which grammatical cohesive devices are realized in the Language and Literature abstracts of undergraduate dissertations submitted to the Department of English of a public Ghanaian university. The study also sought to establish the similarities and dissimilarities in the use of these cohesive devices in the two corpora.

In conclusion to their study, in the abstracts of undergraduate dissertations, all four grammatical cohesive devices (conjunction, reference, substitution and ellipses) are used, conjunction and reference elements being preponderantly used. The study also showed that similar linguistic resources are used to realize these cohesive devices in both the Language and Literature abstracts. Second, the similarities are much more evident than the differences in the use of grammatical cohesive devices in the Language and Literature abstracts. The study also found that some undergraduate students of English of the University of Cape Coast lack sophistication in the extent to which they utilized these cohesive devices.

The objective of this study is to describe the use of cohesive devices in English descriptive texts written by undergraduate students of STIE KERJASAMA Yogyakarta. 


\section{THEORETICAL REVIEW}

\subsection{The Definition of Writing}

According to Harris (1993:10), writing is a process that occurs over a period of time, particularly if we take into account the sometimes extended periods of thinking that precede creating an initial draft. Moreover, like playing tennis, writing is an activity made up of several processes, such as thinking what to write and the order to put it in Grundy (1991:7). In the process, writing and thinking are so inseparable, if the writer cannot think clearly about an idea, he cannot write well. On the one hand, if he has creative thinking in the writing process, the actual writing process will be easier. In addition, Crime and Lea (2008: 5) define that writing consists of words and these words are put together in particular formations to make sentences. Sentences are then grouped together into paragraphs. Moreover, Celce-Murcia (2000: 142) defines that writing is the production of the written word that results in a text, but the text must be read and comprehended for communication to occur. As a writer must be able to arrange the words into sentences in the form of the written text in which the reader will eventually understand the ideas and their meaning. Thus, the writer is demanded to pay attention to some aspects of the production of the written text which involves the content, organization, vocabulary use, grammatical use, and mechanical considerations such as spelling and punctuation.

\subsection{The Concept of Cohesion}

According to Hoey (1991), a lot of important works related to the subject matter of cohesion have been published since the early seventies when text analysis was still in its early stages and the flood of publications just mentioned was still more than light rainfall. Studies in cohesion as Hoey points out are no longer likened to a light rainfall. Studies in cohesion have reached a high stage and have gained ground in linguistic studies especially discourse analysis. Hoey (1991) refers to cohesion as rooted in a stratification framework and that its focus on the potential stylistic applications of cohesive studies has provided a starting point for some research studies in stylistics. Additionally, Hoey also refers to the work of Halliday and Hasan (1976) as the more widely known, built heavily upon two earlier works by Hasan, published in (1968) and (1971) which listed and 
classified devices available for linking sentences to each other. Hoey (1991), as a point of departure points out that Halliday and Hasan (1976) have probably had the widest audience not least because theirs is the most detailed description.

Halliday (1976), as cited in Hoey (1991), divided cohesive devices into five types: conjunction, reference, substitution, ellipsis, and lexical cohesion. These are referred to as non structural resources that are used in the surface structures of texts. Halliday and Hasan's cohesion model is obvious between sentences as those within the sentences can also function as structural elements. Hoey (1991) has the opinion that cohesion may be crudely defined as the way certain words or grammatical features of a sentence can connect that sentence to its predecessors (and successors) in text. He further describes that according to the works alluded to, a text is in part organized, in part created, by the presence in each sentence of these elements that require the reader to look to the surrounding sentences for their interpretation. In this sense, Halliday and Hasan (1984) refer to cohesion as a semantic relation between elements in the text and some other element that is crucial to its interpretation. Cohesion as described by Halliday (1991 and 1993) is one of the features that combine to make up the textual component in grammar.

\subsection{Cohesive Devices}

The term cohesive has been defined in various ways. Some researchers apply the term cohesion to the surface structure of the text. Cohesion sometimes is applied to smaller units of language in the text. Other researchers have defined cohesion as continuity in words and sentence structure. Cohesion may be crudely defined as the way certain words or grammatical features of a sentence can connect that sentence to its predecessors (and successors) in a text (Hoey 1991:3). A text is in part organized, in part created, by the presence in each sentence of these elements that require the reader to look to the surrounding sentences for their interpretation. Phenomena that had resisted satisfactory handling within sentence-bound grammars, such as pronominalization, ellipsis, and sentence conjunction, were found in such studies to be not only well handled once textual factors were taken into account but capable in turn of casting light on the nature of text itself. Halliday and Hasan (1976:4) state that the concept of 
cohesion is a semantic one; it refers to relations of meaning that exist within the text, and that define it as a text.

\subsection{Types of Cohesive Devices}

According to Halliday and Hasan (1976) cohesion can be divided into two types: grammatical cohesion and lexical cohesion. The former refers to a combination of terms sentences that form grammatical aspect. The latter refers to a combination of terms between sentences that form lexical component. Grammatical cohesion can be divided into four kinds. They are reference, substitution, ellipsis, and conjunction.

\section{Reference}

Reference is a grammatical cohesion device in a text that can only be interpreted with reference either to some other parts of the text or to the world experienced by the sender and the receiver of the text. The term reference, as used by Halliday and Hasan is an extension of the term as used in philosophy and some types of semantics to mean an act of referring to entities outside the discourse ('in the real world' as it were, although we need to remember that 'real world' can include imaginary worlds, such as we find in fiction or myth). Reference in this sense is not necessarily textually cohesive. For example, when out walking at night, a person might point to the moon and say to a companion, 'Look at that'. In this case, that refers to an entity which is identifiable in the situation of utterance. That is an example of non cohesive exophoric reference or reference outside the text. If, on the other hand, the speaker says, 'Look at the moon' and the companion replies, 'I can't see it' or 'Where is it?' with it referring to the previously mentioned moon, and cohesion is established. The latter is known as endophoric reference or reference to something within the text (in this case the short exchange about the moon). Strictly speaking, of course, it is speakers or writers who refer to entities, using expressions for the purpose, but as a shorthand device we often talk about words or expressions referring to each other and say that endophoric reference occurs when two or more expressions refer to the same entity. Endophoric reference is classified into cathaphoric and anaphoric reference. Cataphoric is forward pointing, in the sense that 
in a text the unnamed expression, usually a pronoun or demonstrative, appears first and the named expression appears second.

Halliday and Hasan (1976:37) state that there are three types of reference: personal, demonstrative, and comparative. Personal reference is reference by means of function in the speech situation, through the category of person. Demonstrative reference is reference by means of location, on a scale of proximity. Comparative reference is indirect reference by means of identity or similarity. What is known as personal reference is dependent on the use of personal pronouns ( $\mathrm{I}$, she, he, it, they, me, etc) possessive adjectives (my, your, their, etc), and possessive pronouns (mine, yours, theirs). Demonstrative reference is dependent on the use of determiners (this, these, that, those) and adjuncts (here, now, then, there), and comparative reference uses adjectives like same, other, identical, better or their adverbial counterparts identically, similarly, less, and soon.

\section{Substitution}

A substitution tie within a passage is employed to substitute one word for another, where the latter word in the passage functions as the substitution and is employed instead of repeating the former word or clause in the text. Substitution tie sub-domains include (a) noun replacements (e.g., Ali found a big apple. Maryam found a small one.), and (b) verb replacements (e.g., I suggested Ali would do the assignments, and he did.). In both examples above, substitution tie (one, did) interpretation relies on the context established in the preceding sentence. Substitution ties occur more often in speaking than in writing (Halliday \& Hasan, 1976).

\section{Ellipsis}

An ellipsis creates connection in writing and lets the writer to delete (a) a noun (e.g., Ali had a red apple. Mine was green.), (b) a verb (e.g., Ali bought a big house, but Maryam a small house.), or (c) a clause following the presupposed element (e.g., Q: Do you study English? A: Yes.). The intended supposition can be inferred from the previous sentence and context permitting the referent to be omitted from following sentences. As with substitution ties, ellipsis ties occur more frequently in speaking than in writing (Halliday \& Hasan, 1976). 


\section{Conjunction}

A conjunction connects two structurally independent units. Conjunction consists of subdomains contain (a) additive conjunctions (e.g., and, or), (b) adversative conjunctions (e.g., however, in addition, although), (c) causal conjunctions (e.g., due to, therefore, thus), and (d) temporal conjunctions (e.g., first, next, finally). The sentence, "Ali went to bed but he didn't sleep" has two independent clauses connected by the adversative conjunction but, letting the reader to connect the latter phrase to the former. (Halliday \& Hasan, 1976).

\section{Lexical Cohesion}

Lexical cohesion is created through the writer's choice of specific vocabulary (Halliday \& Hasan, 1976). New lexical items affect the lexical category's complexity and can be added to the lexical set. For example, the lexical set for door extends as the context in which door occurs changes such that "door is in contrast with gate and screen; also with window, wall, floor, and ceiling; with knob, handle, panel, and sill; with room, house, hall; with entrance, opening, portal" (p. 63). Lexical cohesion can also be achieved through derivations of the same word (e.g., write, wrote, written, writing). Within the lexical domain, Halliday and Hasan (1976) recognized two lexical cohesive sub-domains -reiteration and collocation. A reiteration can be (a) a repetition of the same word (e.g., my house has a window. I am cleaning the window.), (b) a synonym or near synonym of the referent (e.g., she exercises every morning. The aerobic is refreshing.), or (c) a super-ordinate of the referent often preceded by the word the (e.g., I bought a clothe. I wear the coat everywhere!). 2. Collocations that are a combination of two or more words that fall in the middle between idioms (e.g., spill the beans) and free word combinations (e.g., beautiful girl) which allow a limited degree of substitution of their lexical components (e.g., do your best and try your best but not perform your best).

\section{METHODOLOGY}

This research used the students' descriptive texts in the same topic as the main data. Every student wrote one English text and one Indonesia text. So the researcher took 20 texts from 10 students consisting 10 texts in English and 10 texts in Indonesian. The subjects of the research are the $3^{\text {rd }}$ semester students of undergraduate program. They are the students of Banking Department of STIE KERJASAMA Yogyakarta. There are 46 
students of English subject class, which is divided into two classes. The researcher took randomly 20 students as the subject of the study. They are considered as the intermediate level of English learners.

The technique used in this research is descriptive analysis. Descriptive analysis functions as a technique used to describe something in details. In this research, the researcher aimed to identify, classify, tabulate, compare, and interpret the cohesiveness of students' writing .

\section{FINDINGS AND DISCUSSIONS}

\subsection{The Use of Cohesive Devices in English Descriptive Texts}

In order to make this research more convincing, the researcher tabulated the data according to Halliday \& Hassan's theory. The data are drawn in the table as follows:

Table 1. The Use of Cohesive Devices In English Text

\begin{tabular}{|c|c|c|c|c|c|c|c|c|c|c|c|c|c|}
\hline \multirow{3}{*}{ NO } & \multirow{3}{*}{ TEXT } & \multicolumn{12}{|c|}{ TYPES OF COHESIVE DEVICES } \\
\hline & & \multicolumn{2}{|c|}{ REFF } & \multicolumn{2}{|c|}{ SUB } & \multicolumn{2}{|c|}{ ELLIP } & \multicolumn{2}{|c|}{ CONJ } & \multicolumn{2}{|r|}{ LEX } & \multicolumn{2}{|c|}{ TOTAL } \\
\hline & & $\mathrm{F}$ & $\%$ & $\mathrm{~F}$ & $\%$ & $\mathrm{~F}$ & $\%$ & $\mathrm{~F}$ & $\%$ & $\mathrm{~F}$ & $\%$ & $\mathrm{~F}$ & $\%$ \\
\hline 1 & Text 1 & 9 & $50.0 \%$ & 1 & $5.6 \%$ & 0 & $0.0 \%$ & 3 & $16.7 \%$ & 5 & $27.8 \%$ & 18 & $100 \%$ \\
\hline 2 & Text 2 & 6 & $50.0 \%$ & 0 & $0.0 \%$ & 0 & $0.0 \%$ & 2 & $16.7 \%$ & 4 & $33.3 \%$ & 12 & $100 \%$ \\
\hline 3 & Text 3 & 8 & $50.0 \%$ & 0 & $0.0 \%$ & 0 & $0.0 \%$ & 3 & $18.8 \%$ & 5 & $31.3 \%$ & 16 & $100 \%$ \\
\hline 4 & Text 4 & 6 & $50.0 \%$ & 0 & $0.0 \%$ & 1 & $8.3 \%$ & 1 & $8.3 \%$ & 4 & $33.3 \%$ & 12 & $100 \%$ \\
\hline 5 & Text 5 & 4 & $57.1 \%$ & 0 & $0.0 \%$ & 0 & $0.0 \%$ & 1 & $14.3 \%$ & 2 & $28.6 \%$ & 7 & $100 \%$ \\
\hline 6 & Text 6 & 10 & $62.5 \%$ & 0 & $0.0 \%$ & 0 & $0.0 \%$ & 2 & $12.5 \%$ & 4 & $25.0 \%$ & 16 & $100 \%$ \\
\hline 7 & Text 7 & 2 & $20.0 \%$ & 0 & $0.0 \%$ & 0 & $0.0 \%$ & 4 & $40.0 \%$ & 4 & $40.0 \%$ & 10 & $100 \%$ \\
\hline 8 & Text 8 & 4 & $30.8 \%$ & 0 & $0.0 \%$ & 0 & $0.0 \%$ & 2 & $15.4 \%$ & 7 & $53.8 \%$ & 13 & $100 \%$ \\
\hline 9 & Text 9 & 3 & $23.1 \%$ & 2 & $15.4 \%$ & 0 & $0.0 \%$ & 4 & $30.8 \%$ & 4 & $30.8 \%$ & 13 & $100 \%$ \\
\hline 10 & Text 10 & 5 & $38.5 \%$ & 0 & $0.0 \%$ & 0 & $0.0 \%$ & 2 & $15.4 \%$ & 6 & $46.2 \%$ & 13 & $100 \%$ \\
\hline Per & $\begin{array}{l}\text { otal } \\
\text { entage }\end{array}$ & 57 & $43.8 \%$ & 3 & $2.3 \%$ & 1 & $0.8 \%$ & 24 & $18.5 \%$ & 45 & $34.6 \%$ & 130 & $100 \%$ \\
\hline
\end{tabular}

The data findings above shows that all types of cohesive devices are found in the English text. Three kinds of cohesive devices are frequently used by the students in English text; namely reference, lexical cohesion, and conjunction. The data on the table shows that the highest frequency of occurrence in English texts is reference (43.8\%). This is because 
in terms of reference, the information to be retrieved is the referential meaning, the identity of the particular things or class of things that is being referred to and the cohesion lies in the continuity of reference, whereby the same thing enters into the discourse a second time.

A rather large number of high- encounter grammatical cohesion is lexical cohesion $(34.6 \%)$. The use of lexical cohesion is dominated by repititions. Another cohesive device that was found by the researcher is hyponymy.

Third place belongs to conjunction with $18.5 \%$ cases. That conjunction plays an important role in expressing organization of a text is the reason for this. The conjunctive words or phrases describe the logical relationship of phrases, sentences and paragraph that help to create a cohesive text. It is relevant to the use of many conjunctions in the English descriptive texts, making it more easily comprehensible to readers.

The lowest frequency of occurrence is substitution and ellipsis. There are three cases $(2.3 \%)$ of subtitution found in the text. Whereas ellipsis only occurred once $(0.8 \%)$ from the overall English texts. This may result from the characteristics of Banking Departemen students in particular and ESP in general, which is required to be accurately and clearly stated otherwise ambiguity is likely to arise and misunderstanding can lead to a far- reading consequences. The complete data on the use of cohesive devices in English text are presented in appendix 1.

The following are the sections covering the analysis and discussion of data, guided by the research questions as presented in table 1 ;

\subsubsection{References}

The analysis of the data shows that there are three kinds of references used in the English descriptive texts by the students, namely personal reference, demonstrative reference, and comperative references. They included elements in the texts such as it, its, this these, that, those, and the largest for comparative reference. Examples of the use of reference to achieve cohesion within the text are given below:

1) Bank Mega is one of a private bank in Indonesia. It is not as familiar as the others. It is still strange for some Indonesian people especially those who live in villages. The majority of its customers come from reach people who live in the town. (English text 1 : sentence number $1-4)$. 
2) Bank Muamalat was established on 1st November 1991. It is an Islamic bank of Indonesia which operates under the regulation of Islam rules. According to its own website, Bank Mumalat is currently providing services to more than 4.3 million customers through 457 outlets spread across 33 provinces in Indonesia. (English text 2: sentence 1-3).

3) Bank Negara Indonesia is Indonesian State Bank, commonly known as BNI. It has branches primarily in Indonesia. (English text 3: sentence 1-2)

4) In this bank, we can open saving accounts, save and transfer money, and take credits. (English Text 3: Sentence 8)

5) Bank BCA is the largest private bank in Indonesia. (English Text 4: sentence number 1).

In example 1 "Bank Mega is one of a private bank in Indonesia. It is not as familiar as the others. It is still strange for some Indonesian people especially those who live in villages. The majority of its customers come from reach people who live in the town", the subject pronoun it in sentence (2) clearly makes a backward reference to the subject Bank Mega mentioned in the previous sentence. This kind of reference is categorized into endophoric reference because the pronoun refers to something within the text. In addition, the pronoun it in sentence (3) is also classified into endophoric reference because it refers to something within the text. Meanwhile, the possessive pronoun its in sentence (4) refers to the phrase PT Bank Karman mentioned in the previous sentence. This kind of reference is also catagorized into endophoric reference. In addition to the sub types of reference, Halliday and Hassan also subclassified endophoric reference into anaphoric and cataphoric reference. Anaphoric is preceding pointing while cataphoric is forward pointing. Due to the fact that, the personal references used in text 1 are catagorized into anaphoric references because all of the antecedents occurred in the preceding references. Similiarly, The pronoun it in example 2 "Bank Muamalat was established on 1st November 1991. It is an Islamic bank of Indonesia which operates under the regulation of Islam rules" clearly refers to the subject Bank Muamalat mentioned in the previous clause. This kind of reference is classified into anaphoric reference because the pronoun refers to something within the 
text and the reference appears in the preceding pronoun. Whereas the possessive pronoun its in sentence 3 "According to its own website, Bank Mumalat is currently providing services to more than 4.3 million customers through 457 outlets spread across 33 provinces in Indonesia" is classified into cataphoric reference due to the fact that the reference Bank Muamalat occurs in the following. In example 3 "Bank Negara Indonesia is Indonesian State Bank, commonly known as BNI. It has branches primarily in Indonesia", the personal reference it makes a backward reference to the subject Bank Negara Indonesia mentioned in the previous sentence. This reference is categorized into endophoric reference because the pronoun refers to something within the text. The pronoun it is also sub-classified into anaphoric reference because the antecedent of pronoun occures in the preceding reference.

A different analysis prevails for example 4 "In this bank, we can open saving accounts, save and transfer money, and take credits". The reference used in the text is demonstrative reference. The reference this demonstrates the preceding reference Bank BNI. Hence, this kind of reference is catagorized into endophoric reference. In addition, it also indicates the anaphoric reference because the reference occurs in the preceding sentence.

The last case of reference found in the Students' English descriptive texts is the use of comparative reference as quoted in example 5 "Bank BCA is the largest private bank in Indonesia". The phrase the largest is identified as comparative reference and categorized into endopohoric reference because the reference refers to something within the text. In addition, the types of comparative reference is respectively classified into superlative.

\subsubsection{Substitutions}

The analysis found that substitution is scarcely used to achieve cohesion; only three instances were observed in the English texts. The examples below illustrate the use of substitution as a cohesive device in one of the Engslih descriptive texts of the students:

6) Bank Mega is one of a private bank in Indonesia. It is not as familiar as the others. (English text 1: sentence 1-2) 
7) From 1997 until today, Mayapada became a public bank under the name of PT. Bank Mayapada Internationa. The main business activities of the company are to collect public funds and distribute those funds through borrowing in the form of credit facilities. (English text 9: sentence 4-5)

In example 6, the phenomenon of substitution in the text can be seen from the subtitution of the pharse the other banks by the others. It may be interpreted in a complete sentence as Bank Mega is one of a private bank in Indonesia. It is not as familiar as the other banks in Indonesia. This subtitution is classified into pharasal subtitution due to the fact that the writer of the text subtitutes a pharse by another pharse. Another case of subtitution also can be seen in example 7. In this case, the pharse the company subtitutes the word Mayapada. Halliday and Hasan refer to this kind of substitution as nominal substitution because the writer of the text subtitutes the subject mayapada (noun).

\subsubsection{Ellipsis}

Like substitution, ellipsis was rarely used in the English descriptive texts. Based on the data finding, an elliptical construction was realized in only one instance in the text:

8) As the largest private bank in Indonesia, it is not difficult to find Bank BCA in almost every district in Indonesia and neither is the ATM. (English text 4: Sentnce 5)

The use of ellipsis in example 8 is realized. The writer of the text reduced a clause using clausal ellipsis in negative sentence with neither. In sentence "it is not difficult to find Bank BCA in almost every district in Indonesia and neither is the ATM", the writer of the text made an ellipsis in the second sentence. The possible interpretation of the complete sentence may be interpreted as it is not difficult to find Bank BCA in almost every district in Indonesia and it is also not difficult to find the ATM in almost every district in Indonesia.

\subsubsection{Conjunctions}

The analysis of the data shows that there some kinds of conjucntions found in the students English text. As presented table 1, conjuction takes the third place of the most frequence types of cohesive devices udes by the students in English text. The examples below illustrate the use of conjunction as a cohesive device in the English descriptive texts: 
9) As the first Bank of Syariah, Bank Muamalat committed to deliver banking services that are not only complied with syariah, but also competitive and accessible to the public until the remote area of Indonesia. (English text 2: sentence 8)

10) In this bank, we can open saving accounts, save and transfer money, and take credits. (English text 3: sentence 8)

11) In 2007, Bank Sinarmas facilitated an integrated banking technology like the Phone Banking, Internet Banking, and Automatic Teller Machine (ATM) (English text 8: sentence 7)

The conjunctive used in example 9 is additive conjunctions. The conjunctive not only but also connects the clause "banking services that are complied with syariah and banking services that are competitive and accessible to the public". In this case, The conjunctive not only but also connects two dependent clauses that are syntactically interchangeable. Meanwhile, In example 10 and 11 "In this bank, we can open saving accounts, save and transfer money, and take credits. In 2007, Bank Sinarmas facilitated an integrated banking technology like the Phone Banking, Internet Banking, and Automatic Teller Machine", the conjunctive and has been used as an additive conjunction to give additional information. They a re $r$ espectively considered to be coordinative conjunctive or additive conjunctions. The conjunctive and connects two linguistic units that are grammatically equal or similar.

\subsubsection{Lexical Cohesions}

According to the data analysis, lexical cohesion plays an important role in the students English text. It takes the second posistion of the most frequent of cohesive devices used in the text. The use of lexical cohesion is dominated by repititions. The examples below illustrate the use of lexical cohesion as a cohesive device in some of the Engslih descriptive texts of the students:

12) According to its own website, Bank Mumalat is currently providing services to more than 4.3 million customers through 457 outlets spread across 33 provinces in Indonesia. Bank Muamalat is also supported by a network of alliances through 
more than 4000 Online Post Office throughout Indonesia, 1996 ATMs, and 95,000 merchant debits. (English text 2: sentence 3-4)

13) As a state bank, Bank BNI is very popular for Indonesian people. It is very easy to find Bank BNI in every place even in remote area.

14) Bank BCA is the largest private bank in Indonesia. Bank BCA was established on February 21, 1957. ((English text 4: sentence 1-2)

The use of lexical cohesion in example 11 is realized by repetition and hyponymy. The repetition of Bank Muamalat indicates the realization of lexical cohesion.

Meanwhile, the hyponymy appears in sentence (4). "Bank Muamalat is also supported by a network of alliances through more than 4000 Online Post Office throughout Indonesia, 1996 ATMs, and 95,000 merchant debits”. In this case, the hyponym of Online Post Office, ATM, and merchant debits are considered to be part of linguistic unit from network of alliances.

In example 12 “According to its own website, Bank Mumalat is currently providing services to more than 4.3 million customers through 457 outlets spread across 33 provinces in Indonesia. Bank Muamalat is also supported by a network of alliances through more than 4000 Online Post Office throughout Indonesia, 1996 ATMs, and 95,000 merchant debits", the realization of lexical cohesion in is realized by repetition. Additionally, in example 13 “As a state bank, Bank BNI is very popular for Indonesian people. It is very easy to find Bank BNI in every place even in remote area", the repetition of the word Bank $B N I$ indicates the use of lexical cohesion in terms of repititions. The writer of the text prefered to used the same word (Bank BNI) than raplaced it by a pronoun. Moreover in example 14 "Bank $\boldsymbol{B C A}$ is the largest private bank in Indonesia. Bank BCA was established on February 21, 1957”, the word Bank BCA has been used as part of cohesive devices in term of lexical cohesion. The repetition of the word Bank BCA indicates the lexical cohesion in terms of repetition.

\section{CONCLUSIONS}

The researcher examined the extent to which cohesive devices are realised in the English texts of undergraduate students at STIE KERJASAMA Yogyakarta's Banking 
Department. Numerous conclusions can undoubtedly be drawn from data analysis and discussion: To begin, all types of cohesive devices are identified in English texts (reference, substitution, ellipsis, conjunction, and lexical cohesion).

Second, cohesive devices in English texts are dominated by reference, conjunction, and lexical cohesion. The lowest frequency of occurrence are substitution and ellipsis.

Conjunctions appear to be frequently used in English text. The frequent use of conjunctions in English descriptive texts in general, and additives in particular, may reflect the authors' strong desire to explicitly itemise their points or advance their arguments chronologically. It is extremely frequently used in texts in terms of lexical cohesion. Simple repetition is the most common application of lexical cohesion in English texts. As with other forms of language, repetition emphasises and clarifies concepts. Along with repetition, hyponymy occurs in English texts.

\section{REFERENCES}

Afful. J.B.A and Nartey M. 2014. Cohesion in the Abstracts of Undergraduate Dissertations: An Intra-disciplinary Study in a Ghanaian University. Journal of ELT and Applied Linguistics (JELTAL) Volume 2-Issue 1, January, 2014 ISSN: 23476575 .

Creme, Phyllis and Mary R. Lea. 2008. Writing at University: A guide for student $\left(3^{\text {rd }}\right.$ Edition). Maidenhead, UK: Open University Press.

Celce-Murcia M, and Olstain, Elite. 2000.Discourse and Context in LanguageTeaching. New York: Combridge University Press.

Brown, H. D. 2007. Principles of Language Learning and Teaching (4 $4^{\text {th }}$ ed.) New York: Pearson Education, Inc.

Grundy, Peter. 1991. Beginning to Write: Writing Activities for Elementary and Intermediate Learners. Cambridge: Cambridge University Press. 
Halliday, M.A.K., \& Hasan, R. 1976. Cohesion in English. London: Longman

Halliday, M.A.K., \& Hasan, R. 1989. Language, context, and text: Aspects of language in a social-semiotic perspective ( $2^{\text {nd }}$ Ed.) Oxford: OUP.

Halliday, M.A.K., \& Matthiessen, C. 2004. An Introduction to Functional Grammar, (3 ${ }^{\text {rd }}$ Ed.). London: Hodder Education.

Harris, J. 1993. Introducing Writing. London: Penguin

Hoey, M. 1991. Patterns of Lexis in Text. Oxford: Oxford University Press.

Ninsiana W. 2014. Grammatical Cohesion Devices on The Indonesian Translation of English Bidding Document. International Journal of Language and Linguistics. Vol. 2, No. 6, 2014, pp. 361-367. Availabe online on http://www.sciencepublishinggroup.com/j/ijll. 